\begin{tabular}{|l|l|l||}
\hline \multicolumn{2}{|c|}{ PublisherInfo } \\
\hline \hline PublisherName & $:$ & BioMed Central \\
\hline \hline PublisherLocation & $:$ & London \\
\hline \hline PublisherImprintName & $:$ & BioMed Central \\
\hline \hline
\end{tabular}

\title{
Same-sex fungi can mate
}

\begin{tabular}{|l|l|l||}
\hline \multicolumn{2}{|c|}{ ArticleInfo } \\
\hline \hline ArticleID & $:$ & 5080 \\
\hline \hline ArticleDOI & $:$ & $10.1186 /$ gb-spotlight-20050426-01 \\
\hline \hline ArticleCitationID & $:$ & spotlight-20050426-01 \\
\hline \hline ArticleSequenceNumber & $:$ & 56 \\
\hline \hline ArticleCategory & $:$ & Research news \\
\hline ArticleFirstPage & $:$ & 1 \\
\hline \hline ArticleLastPage & $:$ & 3 \\
\hline \hline & & RegistrationDate : 2005-4-26 \\
\hline ArticleHistory & $:$ & OnlineDate \\
\hline \hline ArticleCopyright & $:$ & BioMed Central Ltd2005-4-26 \\
\hline \hline ArticleGrants & $:$ & \\
\hline \hline ArticleContext & $:$ & 130596611 \\
\hline \hline
\end{tabular}


Members of the same sex of a pathogenic fungal species can mate and produce offspring, scientists report in the April 21 issue of Nature. The finding suggests for the first time that the fungus has developed a novel type of sexual cycle, according to senior author Joseph Heitman at Duke University in Durham, NC.

Cryptococcus neoformans causes life-threatening meningoencephalitis in immunocompromised patients. The fungus has two sexes, alpha and $a$, but the vast majority of $C$. neoformans isolates seen clinically and in the environment are alpha, leaving them with apparently few chances to mate. "Normally when you have sexually reproducing organisms, you find both sexes in roughly equal numbers," Heitman told The Scientist.

During mating, C. neoformansdevelops filaments and spores. Haploid alpha strains can also grow filaments and spores in a process known as fruiting, which researchers thought was asexual and mitotic. To see if diploidization occurred during fruiting, Heitman and colleagues cultured cells from the buds of fruiting haploid alpha strain filaments. Fluorescence-activated cell sorting (FACS) analysis revealed $97 \%$ of them were diploid.

To look at whether fruiting involves chromosome assortment and recombination, the researchers examined spores from a diploid alpha-alpha strain constructed from a pair of strains marked with transgenes for either nourseothricin or neomycin resistance. Nourseothricin and neomycin transgenes showed independent assortment, and FACS analysis revealed that the diploid strain's spores were all haploid. Study of markers throughout spore genomes revealed that recombination occurred at a rate similar to alpha- $a$ sexual reproduction. All progeny possessed unique genotypes, none identical to either parent, consistent with meiotic recombination.

Same-sex mating could help C. neoformans generate the genetic diversity associated with sexual reproduction when the opposite sex is rare, Heitman suggested. "This may explain the emergence of this organism as a successful human pathogen, and one that is distributed worldwide rather than being geographically restricted - as is the case, luckily, with many other human fungal pathogens," he told The Scientist.

"Many organisms are thought to reproduce only asexually because no mating partner has been found," noted Aaron Mitchellat Columbia University, who did not participate in this study. "It raises the possibility that even known sexual organisms have a uniparental sexual-like cycle."

Same-sex mating could shed light on the evolution of sex from asexuality, Heitman added. "If you look at Saccharomyces cerevisiae as a model, if you delete the mating type locus entirely, it mates as mating type $a$ as its default state. You can imagine in the ancestral fungus, the earliest mating type was alpha, and if you put the mating type locus next to a telomere, where it would be subject to silencing, it could then mate as an $a$ cell," he said. "So you can imagine fusion events to make a diploid mutant that could undergo meiosis, and the beginnings of a sexual cycle."

"What's nice here is a better understanding of sexual reproduction in a fungus really quite far apart on the family tree from Saccharomyces, the model we've done the bulk of work on," said Alexander 
Johnson at the University of California at San Francisco, who did not participate in this study. "It would be fascinating to know what twists in meiosis take place when Cryptococcus reproduces in this way."

"How often this happens in nature would be very interesting to know, although it might be tough," said John Taylor at the University of California at Berkeley, who did not participate in this study.

"Instead of using strains inbred for a while in the lab, you can pick alpha strains from nature."

\section{References}

1. X. Lin et al., "Sexual reproduction between partners of the same mating type in Cryptococcus neoformans," Nature, 434:1017-21, April 21, 2005.

2. Joseph Heitman, [http://mgm.duke.edu/microbial/mycology/heitman/]

3. K.J. Kwon-Chung, "Morphogenesis of Filobasidiella neoformans, the sexual state of Cryptococcus neoformans," Mycologia,68:821-33, July-August 1976.

4. K.J. Kwon-Chung, J.E. Bennett, "Distribution of alpha and a mating types of Cryptococcus neoformans among natural and clinical isolates," Am J Epidemiol, 108:337-40, October 1978.

5. Aaron P. Mitchell, [http://cumicro2.cpmc.columbia.edu/Micro_Files/Mitchell_Lab.html]

6. Alexander D. Johnson, [http://cc.ucsf.edu/people/johnson_alexander.html]

7. John Taylor, [http://plantbio.berkeley.edu/ taylor/jt.html] 